\title{
Effects of temperature and salinity on larval survival and development of the western school prawn Metapenaeus dalli
}

\author{
Jason A. Crisp $($ • Gavin J. Partridge • Frances M. L. D'Souza • \\ James R. Tweedley $\cdot$ Navid R. Moheimani
}

Received: 6 September 2016/ Accepted: 26 December 2016/Published online: 28 January 2017

(C) The Author(s) 2017. This article is published with open access at Springerlink.com

\begin{abstract}
The effects of temperature and salinity on the survival and development of larval Metapenaeus dalli were investigated in two experiments. First, the effects of four temperatures of 22.6, 25.8, 29.4 and $32.6{ }^{\circ} \mathrm{C}$ on survival and development time were examined from the Nauplius VI to the Mysis I sub-stage. Survival was significantly lower at $32.6{ }^{\circ} \mathrm{C}$ than at 22.6 and $25.8^{\circ} \mathrm{C}$. Development times differed significantly across all temperatures, decreasing linearly with temperature from $161.5 \mathrm{~h}$ at $22.6{ }^{\circ} \mathrm{C}$ to $74.8 \mathrm{~h}$ at $29.4{ }^{\circ} \mathrm{C}$ then decreased slightly to $71.4 \mathrm{~h}$ at $32.6^{\circ} \mathrm{C}$. Second, the combined effects of three temperatures $(21.4,26.5$ and $\left.29.7^{\circ} \mathrm{C}\right)$ and three salinities $(30,35$ and $40 \%$ ) on survival and development were quantified over a $48 \mathrm{~h}$ period from the Nauplius VI sub-stage. Only salinity was found to influence survival, with peak survival (77.7\%) found to occur at the control salinity $(\sim 35 \%)$. Any increase or decrease in salinity from this value resulted in a decrease in survival, with the lowest salinity tested (30\%) having a significantly negative effect on survival (58.4\%) when compared to the control. Only temperature was found to influence the rate of development, with significant increases in development index values being recorded as temperature increased. The recommended conditions for optimal survival and development of $M$. dalli larvae as determined by this study are, therefore, $25.8{ }^{\circ} \mathrm{C}$ and $35 \%$.
\end{abstract}

Keywords Restocking $\cdot$ Penaeid $\cdot$ Crustacean $\cdot$ Abiotic $\cdot$ Shrimp

\section{Introduction}

The western school prawn Metapenaeus dalli was once the focus of a small commercial and iconic recreational fishery in the Swan-Canning Estuary in Western Australia (Potter et al. 1986). This species is known to complete its life-cycle within this estuary, with maturation and reproduction occurring in water temperatures of $\sim 22-26{ }^{\circ} \mathrm{C}$ and approximately marine salinities (Potter et al. 1986, 1989; Broadley et al. 2017). However, under continued fishing and environmental pressures a significant decline in $M$. dalli abundance occurred, leading to a cessation of commercial fishing activities in the 1970s and greatly reduced recreational fishing

J. A. Crisp $(\bowtie) \cdot$ G. J. Partridge · J. R. Tweedley · N. R. Moheimani

School of Veterinary and Life Sciences, Murdoch University, Perth, Australia

e-mail: j.crisp@murdoch.edu.au

G. J. Partridge

Australian Centre for Applied Aquaculture Research, South Metropolitan TAFE, Fremantle, Australia

F. M. L. D'Souza

Department of Water, Perth, Australia 
effort in the late 1990s (Maher 2002). Despite the reduced fishing pressure, stocks of $M$. dalli in the SwanCanning Estuary have not recovered naturally (Smith et al. 2007). Thus, a restocking program was implemented to bypass the recruitment bottleneck during the early larval stages. As this species had never been cultured before, the development of hatchery techniques were initiated in 2012, with the aim of releasing postlarvae (PL) at sub-stage PL15-20; 25-30 days post-hatch (Jenkins, G. I., Australian Centre for Applied Aquaculture Research, Fremantle, Western Australia, unpublished data).

Successful rearing of penaeid prawn larvae for stocking requires high survival rates to be attained, however, this must be achieved in conjunction with development rates that limit the time larvae spend in the hatchery to reduce operating costs (ASEAN 1978). Two significant environmental factors that influence the survival and development rates of larval crustaceans are water temperature and salinity (Kinne 1963, 1964). The complex early life stages of penaeid prawns are considered to be particularly vulnerable to temperature and/or salinity changes, with high mortality occurring during the larval stages under adverse conditions (Anger 2003). Of the three larval stages Nauplius, Protozoea and Mysis in penaeid prawns, Protozoea stage larvae appear to be the most sensitive to changes in temperature and salinity, and thereby provide an effective proxy for assessing suitable culture conditions for all larval and post-larval life stages (Preston 1985; Zacharia and Kakati 2004).

Studies of the effects of water temperature and salinity on larval penaeid prawns, have demonstrated that salinity has a greater effect on survival than temperature (e.g. Kumlu et al. 2000, 2001; Zacharia and Kakati 2004; Ch and Shailender 2013), although increases in mortality are known to occur at relatively high temperatures (Aktas and Cavdar 2012; Jackson and Burford 2003). In contrast, water temperature has a more pronounced effect on larval development than salinity (Parado-Estepa 1998; Jackson and Burford 2003), with growth rates only shown to be affected by salinity at brackish ranges (Ponce-Palafox et al. 1997; Kumlu et al. 2000). Temperature and salinity have also been show to interact, further exacerbating mortality rates when both factors are at the extremes of their ranges (Ponce-Palafox et al. 1997; Kumlu et al. 2000). For the establishment of rearing protocols, however, it is important to determine the temperature and salinity regime that provides the highest possible development rates without compromising larval survival.

Once preferred water temperatures and salinities for culture are established, they can be used to predict larval survival and growth rates for future planning. This is particularly important in larval stock management from the Protozoea stage, as this is the point at which penaeid larvae switch to exogenous feeding (Dall et al. 1990). It is at this point that hatchery feeding relies on the expensive cultivation of live feeds such as microalgae, which require planning days in advance to produce (D'Souza et al. 2000). Live zooplankton is often used from the Mysis and early post-larval stages with similar planning requirements (ASEAN 1978; Zacharia and Kakati 2004). Without predicting survival and development rates, feeding protocols cannot be calibrated, which may result in increased cultivation costs for live foods and potential negative effects on water quality as a result of over or under feeding.

The purpose of this study was to determine the effects of culture temperature and salinity on $M$. dalli Protozoea stage larvae, acting as proxy for all larval developmental stages, in an effort to maximize survival and optimize development rates for the purpose of increasing the number of hatchery-reared $M$. dalli postlarvae that can be restocked into the Swan-Canning Estuary.

\section{Materials and methods}

\section{Broodstock collection}

Female M. dalli were collected at night from the Swan-Canning Estuary in Perth ( $\left.31^{\circ} 56^{\prime} 50^{\prime \prime} \mathrm{S} 115^{\circ} 54^{\prime} 58^{\prime \prime} \mathrm{E}\right)$, south-western Australia from December 2014 to March 2015, using a hand trawl net that was $1.5 \mathrm{~m}$ high, $4 \mathrm{~m}$ wide and constructed from $9 \mathrm{~mm}$ mesh. Water temperature and salinity during brood stock collection were recorded with a YSI 556 Handheld Multiparameter Instrument (http://www.ysi.com), with temperature and salinity ranges of $22.8-26.6{ }^{\circ} \mathrm{C}$ and $34.2-35.7 \%$ recorded over the course of this study. Maturity was determined as per descriptions by Tuma (1967) and Crisp et al. (2017), with mature prawns immediately transported to the aquaculture facility and placed in aerated holding tanks overnight (ASEAN 1978). Females were then stocked into $300 \mathrm{~L}$ conical base spawning tanks at a density of up to 40 per tank for two to four days. The tanks were filled with seawater at a salinity of $\sim 35 \%$ drawn from a bore sunk through limestone 
rock, accessing near-shore marine water, and aerated constantly and maintained at a temperature of $\sim 26{ }^{\circ} \mathrm{C}$, to approximate conditions in the Swan-Canning Estuary at the time and place of capture. The base of each broodstock tank was fitted with a fine grate that allowed eggs to pass through, separating them from broodstock to prevent any potential cannibalism. Broodstock spawned naturally within $48 \mathrm{~h}$ of capture without eyestalk ablation. After spawning, eggs were collected on 48 and $63 \mu \mathrm{m}$ screens and rinsed, sub-sampled for counting and re-suspended in $300 \mathrm{~L}$ of filtered $(1 \mu \mathrm{m})$ seawater, under constant aeration. Egg quality was assessed by hatch rate, with a value of $>75 \%$ survival post-hatch considered suitable for use in the study (ASEAN 1978).

\section{Larval rearing system}

After spawning, hatched larvae were held until they had entered into the Nauplius (henceforth denoted as ' $\mathrm{N}$ ') VI sub-stage at $\sim 48 \mathrm{~h}$ post-hatch. Morphological characters of each larval sub-stage were identified as per Fig. 1 and Crisp et al. (2016). Briefly, N VI larvae were identified as having two pairs of antennae, mandibles, an eyespot and a posterior end with two groups of spines with three plumose spines and three naked spines each. Protozoea sub-stages (PZ I, II and III) were defined as having a cephalothorax, abdomen and telson, with eye stalks appearing from PZ II and two pairs of rudimentary uropods from PZIII. Mysis I sub stage (M I) exhibits a dorsal spine as a precursor to the rostrum and a tail fan with a telson and two pairs of uropods almost fully formed.

Once larvae reached N VI, they were harvested and stocked at a density of 250 larvae $\mathrm{L}^{-1}$ (D'Souza and Kelly 2000) into $6 \mathrm{~L}$ flat bottom cylindrical glass culture vessels containing $4 \mathrm{~L}$ of $1 \mu \mathrm{m}$ filtered seawater. Once larvae were stocked, experimental salinities and water temperatures were acclimated by lowering or increasing the salinity/temperature at a rate of $1 \%$ or $1{ }^{\circ} \mathrm{C}$ per $15 \mathrm{~min}$, respectively. Salinity was adjusted by adding dechlorinated municipal supply water or hypersaline (60\%) sea water (Instant Ocean, USA), as per methods modified from Kumlu et al. (2000, 2001), while water temperature was adjusted by applying either heated or chilled water to water baths until target temperatures were reached. Water temperature for each experiment was maintained by housing culture vessels in $115 \mathrm{~L}$ temperature-controlled water baths, heated with pre-calibrated Eheim Jager $150 \mathrm{~W}$ aquarium water heaters and monitored with Thermocron TCS temperature loggers every $10 \mathrm{~min}$. A constant salinity was maintained in the culture vessels and monitored daily using an ATAGO PAL-03S digital refractometer. Vessels were exposed to $3.5 \mu \mathrm{mol}$ photons $\mathrm{m}^{-2} \mathrm{~s}^{-1}$ white light with 12:12 $\mathrm{h}$ light:dark photoperiod. The larval cultures were aerated from the base to provide vertical mixing as well as oxygenation.

\section{Feed cultivation}

Larval $M$. dalli were fed a diet comprising two microalgae species obtained from the Australian National Algal Culture Collection held by the Commonwealth Scientific and Industrial Research Organization (CSIRO) in Hobart, Tasmania. The chlorophyte Tetraselmis suecica (CSIRO strain number CS-187) and the diatom Chaetoceros muelleri (CSIRO strain number CS-176) were maintained in batch cultures under 14:10 h light:dark photoperiod with $180 \mu \mathrm{mol}$ photons $\mathrm{m}^{-2} \mathrm{~s}^{-1}$ white fluorescent light, in $15 \mathrm{~L}$ culture vessels with ambient salinity $(\sim 35 \%)$ and temperature $\left(\sim 25{ }^{\circ} \mathrm{C}\right)$. Each species was cultured in Guillard's F2 medium, with sodium metasilicate added at $30 \mathrm{~g} \mathrm{~L}^{-1}$ to the C. muelleri (Ryther and Guillard 1962). To avoid carbon limitation, food grade $\mathrm{CO}_{2}$ was injected to maintain a $\mathrm{pH}$ of 7.4-7.7.

Feeding larvae

Larval feed in culture vessels was maintained daily at $3 \times 10^{4}$ cells $\mathrm{mL}^{-1}$ of $T$. suecica and $9 \times 10^{4}$ cells $\mathrm{mL}^{-1}$ of $C$. muelleri, as per feeding protocols used by the Australian Centre for Applied Aquaculture Research (Jenkins, G. I., Australian Centre for Applied Aquaculture Research, Fremantle, Western Australia, unpublished data). These species were used in a previous study of larval $M$. dalli by Crisp et al. (2016) and Farfantepenaeus brasiliensis Gaxiola et al. (2010) at similar feeding concentration for similar life stages. Feed intake was measured by counting residual cells of each microalgae species in larval culture vessels using a Neubauer haemocytometer, then replacing feed that had been consumed. Water in the culture vessels was 

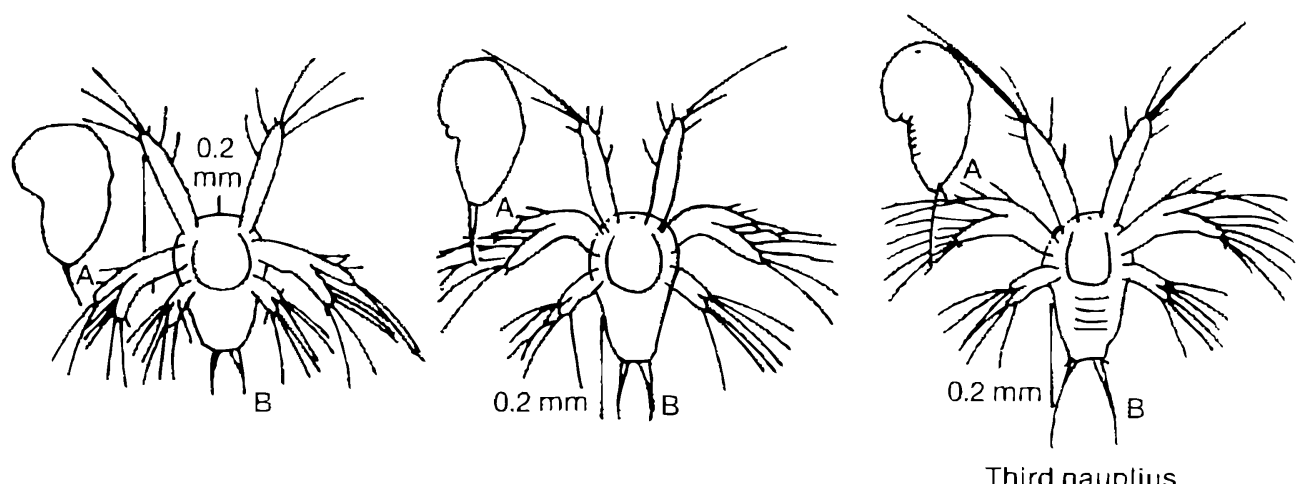

nauplius

First nauplius

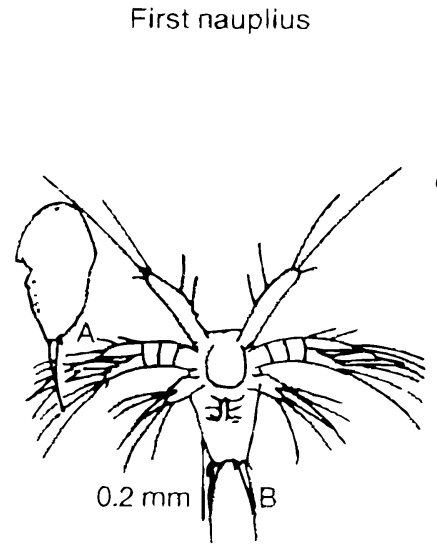

Fourth nauplius
Second nauplius

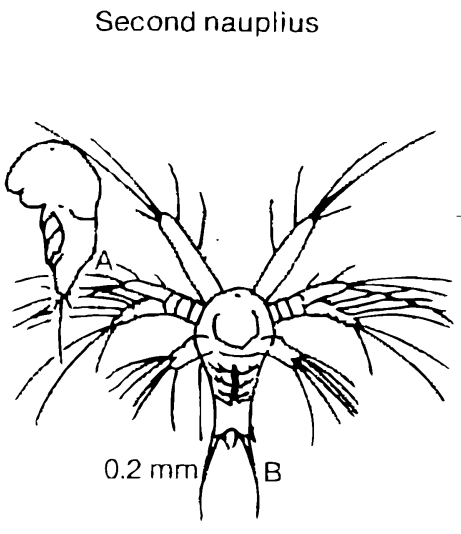

Fifth nauplius

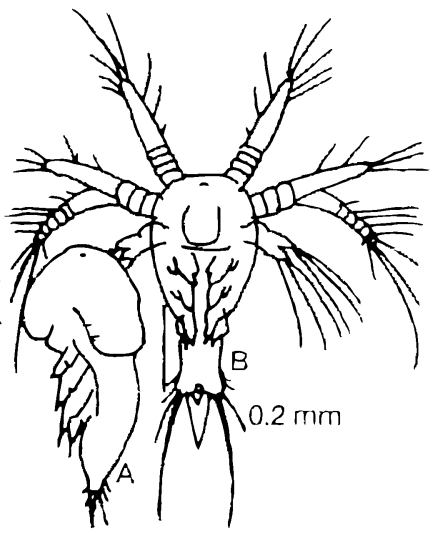

Sixth nauplius
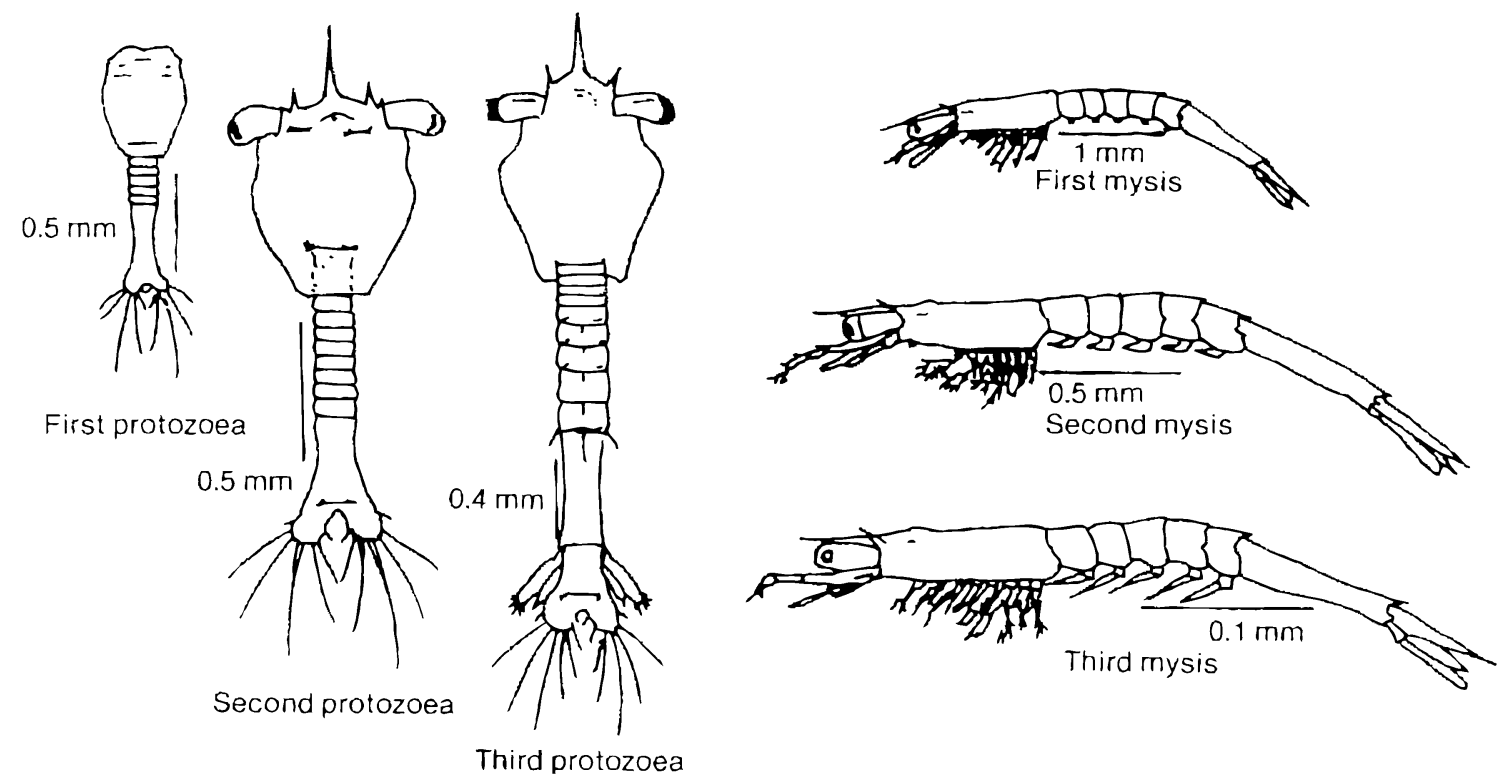

Fig. 1 Representation of the larval life-cycle of penaeid and metapenaeid prawns post hatching from nauplii stages I to VI, through protozoea stages I to III and on to mysis stages I to II (Motoh 1985)

topped up to $6 \mathrm{~L}$ daily with a combination of microalgal feed and fresh seawater, with no greater than $10 \%$ of culture water exchanged per day. Gut contents of the larvae were also briefly examined under a dissecting microscope to confirm that the algal cells were being ingested (D'Souza and Loneragan 1999). 
Experimental design

\section{Effect of temperature}

The influence of four nominal water temperatures, i.e. $23,26,29$ and $32{ }^{\circ} \mathrm{C}$ in the laboratory at a constant salinity of $35 \%$, were assessed on the development time (h) and percentage survival of larval $M$. dalli from N VI, through the protozoal stage (PZ I, II and III) to the Mysis I sub stage (M I). Six replicate culture vessels were used for each of the four temperatures. Development time was calculated as the time taken for $50 \%$ of the larvae in each vessel to reach the M I stage. Single $200 \mathrm{~mL}$ sub-samples were taken every $12 \mathrm{~h}$ from each vessel and each larva staged according to the descriptions in Crisp et al. (2016) and Fig. 1. When M I staged larvae were first observed, each vessel was then sub-sampled every $0.5-1 \mathrm{~h}$. All sampled larvae were carefully returned to the vessels. Once each vessel was found to contain 50\% of animals at the M I stage, time was recorded and triplicate $200 \mathrm{~mL}$ samples were taken and fixed in $5 \%$ tetraborate-buffered formaldehyde solution. All whole larvae that were fixed were assumed to be live at the time of fixation, as larvae are known to be rapidly decomposed by bacteria. Samples were then analyzed for rates of survival by recording the number of whole fixed individuals in each sample and comparing to the initial stocking rate of larvae. This method of determining survival was repeated for the second experiment.

\section{Combined effects of temperature and salinity}

The combined effects of three nominal water temperatures, i.e. 23,26 and $29{ }^{\circ} \mathrm{C}$, and three nominal salinities, i.e. 30,35 and $40 \%$, on the development and survival of $M$. dalli larvae were quantified in a $3 \times 3$ fully factorial design over a $48 \mathrm{~h}$ period, after the temperature experiment was run. Each combination of salinity and temperature was conducted in two vessels per run, with an average of the vessels used to create a replicate value of each treatment regime. The experiment was run three times, creating three replicates for each treatment. Each run commenced from the N VI larval sub-stage, running for a fixed period of $48 \mathrm{~h}$. This time period was chosen to examine the acute combined effects of temperature and salinity on the Protozoea stage of development and was informed by the results of the temperature experiment.

After $48 \mathrm{~h}$, all culture vessels were sampled via triplicate $200 \mathrm{~mL}$ sub-samples and fixed with 5\% tetraborate-buffered formaldehyde, from which survival was determined and the metamorphic sub-stage for each larva was recorded. A development index was calculated for each sub-sample based on that described by Villegas and Kanazawa (1979) and Gaxiola et al. (2010). Each larvae counted was assigned a value for its developmental sub-stage, where PZ I $=1, \mathrm{PZ} \mathrm{II}=2$ and PZ III $=3$. A development index was then calculated, for each sub-sample, by multiplying the sub-stage value (i.e. 1, 2, or 3) by the number of larvae counted at that sub-stage. The product of each sub-stage is then added together then divided by the total number of larvae staged.

Development Index $=$ sum (number of larvae at that stage $\times$ stage value)/total number larvae staged. The more larvae there are at higher stage numbers, the larger the index.

Statistical analysis

\section{Effect of temperature}

Analysis of the percentage values for survival indicated that data ranged both $>80$ and $<20 \%$. As a result this data was subjected to an arcsine square-root transformation as per Field (2009). To determine whether a transformation of the development data was required, the extent of the linear relationship between the $\log _{\mathrm{e}}$ mean and $\log _{\mathrm{e}}$ standard deviation of development time was calculated. Examination of the slope of the linear relationship indicated that a square-root transformation was necessary to meet test assumptions of homogeneity of variance, as per Clarke et al. (2014). Both survival and development time were analyzed separately using a one-way analysis of variance (ANOVA). When ANOVA detected a significant difference among temperatures, post hoc tests were conducted using Tukey's HSD to elucidate the pairs of temperature that were responsible for each of those differences. In this and all tests, a null hypothesis of no significant difference between a priori groups was rejected when $p<0.05$. 


\section{Combined effects of temperature and salinity}

Analysis of the percentage survival data indicated that there were values $>80 \%$, but not $<20 \%$. As a result, a square-root transformation of the data was performed as per Field (2009). Analysis of the relationship between the $\log _{\mathrm{e}}$ mean and $\log _{\mathrm{e}}$ standard deviation of the development index data indicated that no data transformation was required (Clarke et al. 2014). Separate two-way ANOVAs were used to determine whether development index and survival were affected by temperature and/or salinity, or the interaction term. Both factors were considered fixed. If a significant difference in any factor and/or interaction term was detected, post hoc analysis was conducted using Tukey's HSD.

All statistical analyses were conducted using SPSS version 22 software (IBM Corp.). Values for all results are given as mean $\pm 95 \% \mathrm{CL}$.

\section{Results}

Effect of temperature

Mean water temperatures achieved for the nominal temperatures of $23,26,29$ and $32{ }^{\circ} \mathrm{C}$ were $22.6 \pm 0.2$, $25.8 \pm 0.3,29.4 \pm 0.4$ and $32.6 \pm 0.4{ }^{\circ} \mathrm{C}$, respectively. One-way ANOVA demonstrated that the percentage survival of $M$. dalli larvae differed significantly among temperatures $(p<0.001)$. Survival rates were greatest at 25.8 and $22.6{ }^{\circ} \mathrm{C}$, i.e. $73.0 \pm 17.8$ and $66.7 \pm 12.4 \%$, respectively, and lowest at the highest temperature of $32.6^{\circ} \mathrm{C}$, i.e. $26.3 \pm 12.4 \%$ (Fig. 2). Time taken for $M$. dalli larvae to develop from N VI to M I differed significantly among temperatures $(p<0.001)$. Development time decreased markedly from $161.5 \pm 0.9 \mathrm{~h}$ at $22.6{ }^{\circ} \mathrm{C}$ to $74.8 \pm 0.3 \mathrm{~h}$ at $29.4{ }^{\circ} \mathrm{C}$, but only decreased marginally to $71.4 \pm 0.1 \mathrm{~h}$ at $32.6{ }^{\circ} \mathrm{C}$ (Fig. 3).

Combined effects of temperature and salinity

Mean water temperatures achieved for each of the three nominal temperatures tested $\left(23,26\right.$ and $\left.29{ }^{\circ} \mathrm{C}\right)$ were $21.4 \pm 0.3,26.5 \pm 0.2$ and $29.7 \pm 0.4{ }^{\circ} \mathrm{C}$, respectively, with the salinities obtained consistent with nominal salinities (30, 35 and 40\%o). Two-way ANOVA showed no interacting effect of temperature and salinity on either survival $(p=0.480)$ or development rate $(p=0.906)$ of $M$. dalli larvae over a $48 \mathrm{~h}$ culture period. There were, however, two significant main effects, presented below. First, salinity had a significant effect on larval survival $(p=0.010)$, but not temperature $(p=0.570)$. Salinity of $35 \%$ was found to be the best for survival, resulting in a survival of $77.7 \pm 5.0 \%$. This survival was significantly higher than that measured at $30 \%$ o $(58.4 \pm 8.4 \%)$. Survival at $40 \%$ o $(68.4 \pm 7.8 \%)$ was not significantly different from either of the other two salinities (Fig. 4). Second, the reverse was found for larval development such that temperature had a significant effect $(p<0.001)$, but not salinity $(p=0.774)$. Development of larvae was significantly different

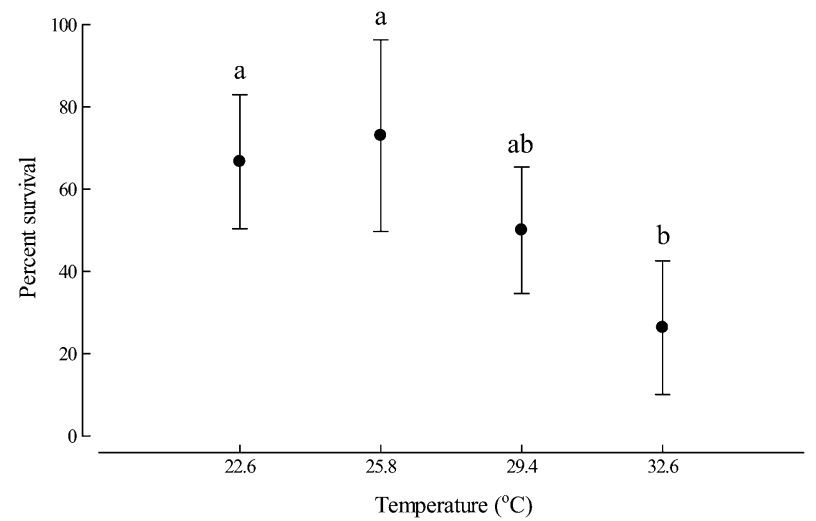

Fig. 2 Mean percentage survival $( \pm 95 \%$ CL) of Metapenaeus dalli larvae during development from Nauplius VI to Mysis I at four different water temperatures. Letters above error bars denote groups of samples identified by Tukey's HSD 


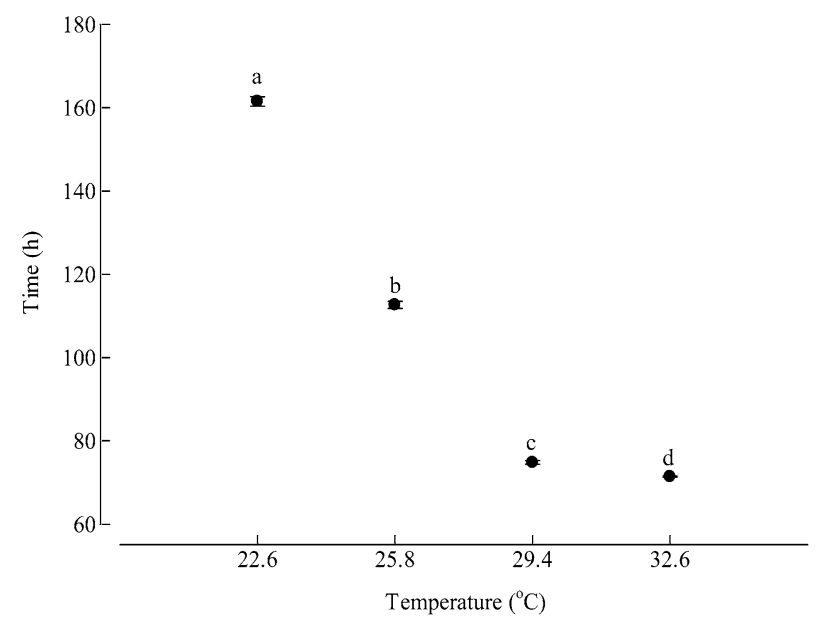

Fig. 3 Average time ( $\pm 95 \%$ CL) taken for Metapenaeus dalli larvae to develop from Nauplius VI to Mysis I at four different water temperatures. Letters above error bars denote groups of samples identified by Tukey's HSD

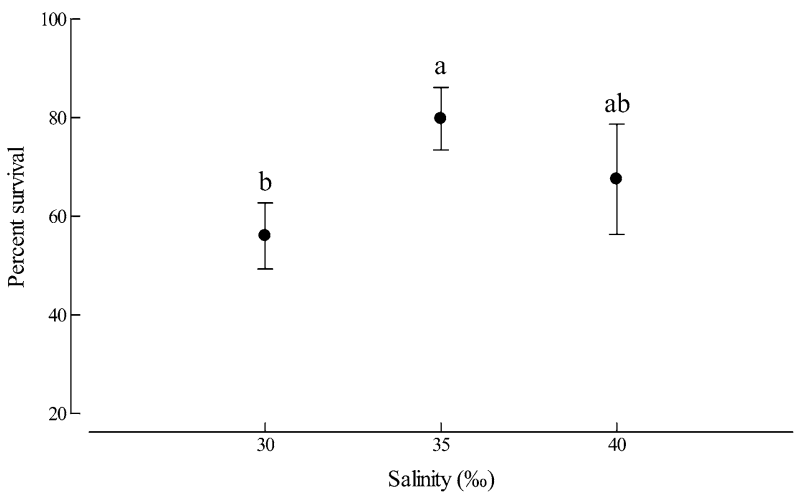

Fig. 4 Mean percentage survival ( $\pm 95 \% \mathrm{CL}$ ) of Metapenaeus dalli larvae over a $48 \mathrm{~h}$ period from N VI sub-stage at three different salinities. Letters above error bars denote groups of samples identified by Tukey's HSD

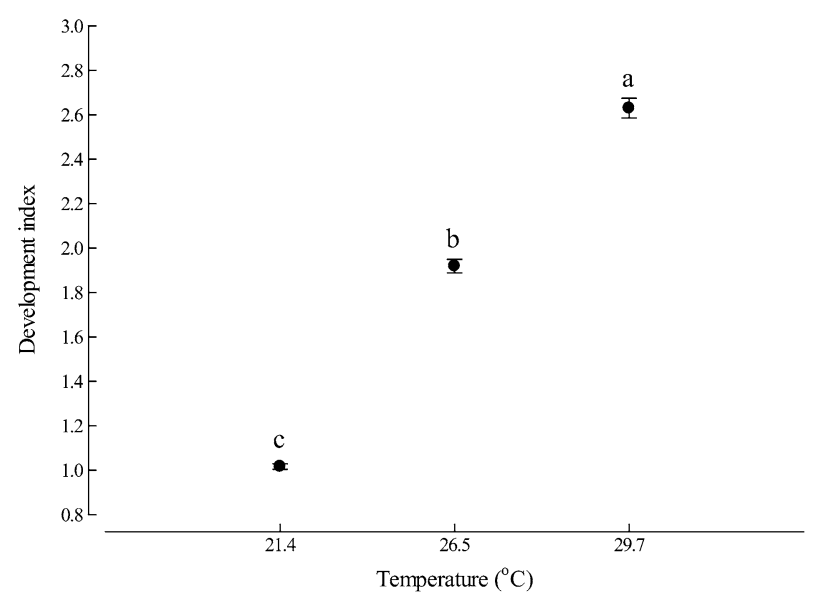

Fig. 5 Mean development index $( \pm 95 \% \mathrm{CL})$ of Metapenaeus dalli larvae over a $48 \mathrm{~h}$ period from N VI sub-stage at three different water temperatures. Letters above error bars denote groups of samples identified by Tukey's HSD

at all three temperatures. A stepwise increase in development rate occurred from the lowest temperature $(1.01 \pm 0)$ to the highest $(2.61 \pm 0.05)$, with some larvae observed reaching a peak development of PZ III in the highest two temperatures tested (Fig. 5). 


\section{Discussion}

\section{Effect of temperature}

In this study, a significant negative impact on survival was detected at the highest temperature tested of $32.6{ }^{\circ} \mathrm{C}$, but not at any other temperature tested, though there appeared to be reduced survival at $29.4{ }^{\circ} \mathrm{C}$. This result is supported by a study by Kumlu et al. (2000), where temperatures above $30{ }^{\circ} \mathrm{C}$ were found to increase mortality in larval Penaeus semisulcatus. Furthermore, preliminary findings by Ponce-Palafox et al. (1997) on larval Litopenaeus vannamei demonstrated that temperatures above $30^{\circ} \mathrm{C}$, with similar salinities to those used in this study, appeared to have a negative effect on survival. The consistency of these results across larval penaeid prawns may indicate there is an upper thermal limit to their biochemical processes.

Results of this study demonstrate that the time taken by $M$. dalli to develop from N VI to M I differ significantly among temperatures. Rapid sequential decreases in development time to M I occurred between temperatures of 22.6 and $29.4{ }^{\circ} \mathrm{C}$, with only a marginal decrease in development time at the highest temperature of $32.6{ }^{\circ} \mathrm{C}$. These results are consistent with that of larval P. semisulcatus (Jackson and Burford 2003 ) and Penaeus monodon (Parado-Estepa 1998), where no significant difference was found in development rates between water temperatures of 29 and $32{ }^{\circ} \mathrm{C}$ during the Protozoea stages.

For commercially cultured crustacean larvae, the effect of water temperatures on larval growth rates are often incorporated into planning tools, such as degree-hours or degree-days calculations (Kittaka et al. 2001, 2002; Gendron and Ouellet 2009), which are used to determine larval duration under various temperatures from spawning to post-larval metamorphosis (Roberts et al. 2012). This allows for the determination of potential feed requirements, which is a particularly important factor in larval culture where forward planning is required for the cultivation of live foods (Stevens 1990). When applied to the temperature ranges tested, it can be assumed that culture temperature should be maintained between 25.8 and $29.4{ }^{\circ} \mathrm{C}$ provided high survival of larvae can be achieved. Reducing temperature by $\sim 3{ }^{\circ} \mathrm{C}$ would increase development time by $>2$ days and thus feed and resource allocation requirements and increasing temperature by $\sim 6{ }^{\circ} \mathrm{C}$ would increase mortality.

\section{Combined effects of temperature and salinity}

Salinity significantly affected survival, while temperature significantly affected the rate of development of larval $M$. dalli, without any interacting effects in the ranges tested. Unlike in the current study, interacting effects of temperature and salinity on survival have been found in other species such as $P$. semisulcatus (Jackson and Burford 2003) and L. vannamei (Ponce-Palafox et al. 1997). However, the results of the current study are consistent with these previous studies when similar temperatures and salinities were compared. In addition, any variation in salinity from 35\% had an apparent negative effect on survival, with a 5\% decrease having a greater effect than a 5\% increase; noting that the increase in salinity to $40 \%$ did not significantly affect survival from that obtained at 35\%. This compares well with the effects of salinity on larval $\mathrm{Me}$ tapenaeus bennettae (Preston 1985) and larval Penaeus merguiensis (Zacharia and Kakati 2004). However, these results contrast with those obtained for juvenile $L$. vannamei and larval $P$. semisulcatus, where although temperature was the primary factor in determining growth rates, salinities far lower than those used in the current study were also found to negatively impact on growth as well as survival (Ponce-Palafox et al. 1997; Kumlu et al. 2000). It may be the case that the energetic demands of osmoregulation under extreme conditions are greater than can be replenished by the larvae. It is only when the extreme ranges are tested that salinity and temperature appeared to interact, placing a combined burden on the energetic reserves of the larvae (Anger 2003).

Finally, the preferred temperatures $\left(25.8\right.$ and $\left.29.4{ }^{\circ} \mathrm{C}\right)$ and salinity $(35 \%)$ determined by this study appear to relate well to the natural spawning environments in the Swan-Canning Estuary, from which broodstock were obtained. Wild $M$. dalli are known to spawn in the middle and lower Swan-Canning Estuary during spring and summer, where the salinity in the river system is $35-38 \%$ and water temperature is $26-28{ }^{\circ} \mathrm{C}$ (Potter et al. 1986), indicating a close relationship between preferred larval hatchery conditions and those expected to influence larvae in the natural population. This relationship appears to be in line with findings on 
M. bennettae, where the water temperatures found where broodstock were obtained, appeared to be the most suitable for larval culture in terms of survival (Preston 1985).

\section{Conclusion}

From this study, the most appropriate temperature and salinity to be used in the cultivation of $M$. dalli larvae were $25.8{ }^{\circ} \mathrm{C}$ and $35 \%$. It is also clear that any increase in temperature and/or variation in salinity may have a negative impact on survival. However, for short-term gains in growth rate, culture temperatures may be increased, providing they remain below $30^{\circ} \mathrm{C}$ as this increase has a negligible effect on survival. Using this information, further research into the nutritional requirements of this species may now be conducted under ideal abiotic rearing conditions.

Acknowledgements Gratitude is expressed to Robert Michael, Bruno Pais and Lindsey Woolley at the Australian Centre for Applied Aquaculture Research (ACAAR), South Metropolitan TAFE, Fremantle, Western Australia for their assistance in the cultivation of microalgae, collection of broodstock and spawning of larvae in the laboratory.

\section{Compliance with ethical standards}

Funding Funding for this project was supplied by the Recreational Fishing Initiatives Fund, a fund supported by Recfishwest and the Department of Fisheries, Western Australia; Fisheries Research and Development Corporation, Australia; Department of Parks and Wildlife, Western Australia; Australian Centre for Applied Aquaculture Research, Western Australia and Murdoch University, Western Australia.

Open Access This article is distributed under the terms of the Creative Commons Attribution 4.0 International License (http:// creativecommons.org/licenses/by/4.0/), which permits unrestricted use, distribution, and reproduction in any medium, provided you give appropriate credit to the original author(s) and the source, provide a link to the Creative Commons license, and indicate if changes were made.

\section{References}

Aktas M, Cavdar N (2012) The combined effects of salinity and temperature on the egg hatching rate, incubation time, and survival until protozoal stages of Metapenaeus monoceros (Fabricius) (Decapoda: Penaeidae). Turk J Zool 37:249-253

Anger K (2003) Salinity as a key parameter in the larval biology of decapod crustaceans. Inverteb Reprod Dev 43(1):29-45

ASEAN (1978) Manual on pond culture of penaeid shrimp. In: Philippines, A. N. C. A. O. T. (eds) Ministry of Foreign Affairs, Manila

Broadley AD, Tweedley JR, Loneragan NR (2017) Estimating biological parameters for penaeid restocking in an Australian temperate estuary. Fish Res 186(2):488-501

Ch SB, Shailender M (2013) Effect of salinity and temperature on larval growth and survival of black tiger shrimp Penaeus Monodon (Fabricius) in laboratory conditions. Int J Bio-Pharm Res 2:72-77

Clarke KR, Gorley RN, Somerfield PJ, Warwick RM (2014) Change in marine communities: an approach to statistical analysis and interpretation, 3rd edn. PRIMER-E, Plymouth, p 260

Crisp JA, Tweedley JR, D'Souza FML, Partridge GJ, Moheimani NR (2016) Larval development of the western school prawn Metapenaeus dalli Racek, 1957 (Crustacea: Decapoda: Penaeidae) reared in the laboratory. J Nat Hist 50(27-28):1699-1724

Crisp JA, D’Souza FML, Tweedley JR, Partridge GJ, Moheimani NR (2017) Quantitative determination of ovarian development in penaeid prawns. J Crustac Biol. doi:10.1093/jcbiol/ruw001

Dall W, Hill BJ, Rothlisberg PC, Staples DJ (1990) The biology of Penaeidae. Adv Mar Biol 27:1-489

D'Souza FML, Kelly GJ (2000) Effects of a diet of a nitrogen-limited alga (Tetraselmis suecica) on growth, survival and biochemical composition of tiger prawn (Penaeus semisulcatus) larvae. Aquaculture 181:311-329

D'Souza FML, Loneragan NR (1999) Effects of monospecific and mixed-algae diets on survival, development and fatty acid composition of penaeid prawn (Penaeus spp.) larvae. Mar Biol 133:621-633

D'Souza FML, Lecossois D, Heasman MP, Diemar JA, Jackson CJ, Pendrey RC (2000) Evaluation of centrifuged microalgae concentrates as diets for Penaeus monodon Fabricius larvae. Aquacult Res 31:661-670

Field A (2009) Discovering statistics using SPSS, 3rd edn. SAGE Publications Inc, London, pp 153-160

Gaxiola G, Gallardo P, Simôes N, Cuzon G (2010) A red shrimp, Farfantepenaeus brasiliensis (Latreille, 1817), larvae feeding regime based on live food. J World Aquacult Soc 41(3):402-410

Gendron L, Ouellet P (2009) Egg development trajectories of early and late-spawner lobsters (Homarus americanus) in the Magdalen Islands, Québec. J Crustac Biol 29:356-363

Jackson CJ, Burford MA (2003) The effects of temperature and salinity on growth and survival of larval shrimp Penaeus semisulcatus (Decapoda: Penaeoidea). J Crustac Biol 23:819-826 
Kinne O (1963) The effects of temperature and salinity on marine and brackish water animals: I. Temperature. Oceanogr Mar Biol Ann Rev 1:301-340

Kinne O (1964) The effects of temperature and salinity on marine and brackish water animals: II. Salinity and temperaturesalinity combinations. Oceanogr Mar Biol Ann Rev 2:281-339

Kittaka J, Kudo R, Onoda S, Kanemaru K, Mercer JP (2001) Larval culture of the European spiny lobster Palinurus elephas. Mar Freshw Res 52:1439-1444

Kittaka J, Stevens B, Teshima S, Ishikawa M (2002) Larval culture of the king crabs Paralithodes camtschaticus and P. brevipes. Crabs in Cold Water Regions: Biology, Management, and Economics. Anchorage, pp 189-209

Kumlu M, Eroldogan O, Aktas M (2000) Effects of temperature and salinity on larval growth, survival and development of Penaeus semisulcatus. Aquaculture 188:167-173

Kumlu M, Eroldogan O, Aktas M, Sağlamtimur B (2001) Larval growth, survival and development of Metapenaeus monoceros (Fabricius) cultured in different salinities. Aquacult Res 32:81-86

Maher J (2002) Where have all the swan-canning prawns gone. West Fish 2002:20-21

Motoh H (1985) Biology and ecology of Penaeus monodon. In: Proceedings of the first international conference on the culture of penaeid prawns/shrimps, 4-7 December 1984, Iloilo City, Philippines. Aquaculture Department, Southeast Asian Fisheries Development Center, pp 27-36

Parado-Estepa FD (1998) Survival of penaeus monodon post larvae and juveniles at different salinity and temperature levels. Isr J Aquacult Bamidgeh 50:174-183

Ponce-Palafox J, Martinez-Palacois CA, Ross LG (1997) The effects of salinity and temperature on the growth and survival rates of juvenile white shrimp, Penaeus vannamei, Boone, 1931. Aquaculture 157:107-115

Potter IC, Penn JW, Brooker KS (1986) Life cycle of the western school prawn, Metapenaeus dalli Racek, in a Western Australian estuary. Aust J Mar Freshw Res 37:95-103

Potter IC, Baronie FM, Manning RJG, Loneragan NR (1989) Reproductive biology and growth of the western school prawn, Metapenaeus dalli, in a large Western Australian estuary. Aust J Mar Freshw Res 40:327-340

Preston N (1985) The combined effects of temperature and salinity on hatching success and the survival, growth, and development of the larval stages of Metapenaeus bennettae (Racek and Dall). J Exp Mar Biol Ecol 85:57-74

Roberts SD, Dixon CD, Anderacchio L (2012) Temperature dependent larval duration and survival of the western king prawn, Penaeus (Melicertus) latisulcatus Kishinouye, from Spencer Gulf, South Australia. J Exp Mar Biol Ecol 411:14-22

Ryther JH, Guillard RR (1962) Studies of marine planktonic diatoms: III. Some effects of temperature on respiration of five species. Can J Microbiol 8(4):447-453

Smith K, Lenanton R, Valesini F (2007) Preliminary survey to determine the abundance of river prawns (Metapenaeus dalli) in the Swan-Canning Estuary. Report to the Swan River Trust, Perth, p 11

Stevens BG (1990) Temperature-dependent growth of juvenile red king crab (Paralithodes camtschatica) and its effects on sizeat-age and subsequent recruitment in the eastern Bering Sea. Can J Fish Aquat Sci 47:1307-1317

Tuma D (1967) A description of the development of primary and secondary sexual characters in the banana prawn, Penaeus merguiensis de Man (Crustacea: Decapoda: Penaeidae). Mar Freshw Res 18:73-88

Villegas CT, Kanazawa A (1979) Relationship between diet composition and growth rate of the zoeal and Mysis stages of Penaeus japonicus Bate. Fish Res J Philippines 4:32-40

Zacharia S, Kakati V (2004) Optimal salinity and temperature for early developmental stages of Penaeus merguiensis de Man. Aquaculture 232:373-382 